\title{
Effects of auxin and urea derivatives on adventitious rooting in chestnut and oak microshoots
}

\author{
Jesús M. Vielba ${ }^{\mathrm{a}}$, Nieves Vidal ${ }^{\mathrm{a}}$, Ada Ricci ${ }^{\mathrm{b}}$, Ricardo Castro ${ }^{\mathrm{a}}$, \\ Purificación Covelo ${ }^{\mathrm{a}}$, M. Carmen San-Joséa and Conchi Sánchez ${ }^{\mathrm{c}}$
}

aDepartment of Plant Physiology, Instituto de Investigaciones Agrobiológicas de Galicia, Consejo Superior de Investigaciones Cientificas (IIAG-CSIC), Santiago de Compostela, Spain; bipartimento di Scienze Chimiche, della Vita e della Sostenibilità Ambientale. Unità di Biologia Evolutiva e Funzionale, Università de Parma, Parma, Italy;

${ }^{\mathrm{c}}$ Department of Plant Physiology, Instituto de Investigaciones Agrobiológicas de Galicia, Avda de Vigo s/n, Santiago de Compostela, A Coruña, 15705, Spain. email: conchi@iiag.csic.es

Israel Journal of Plant Sciences

https://dx.doi.org/10.1163/22238980-20191113

\begin{abstract}
The present study investigated how auxin concentration and the method of application affected the formation of adventitious roots in microshoots of chestnut (Castanea sativa) and oak (Quercus robur). The activity of two urea derivatives (2, 3-MDPU and 3, 4-MDPU) was also evaluated. Microshoots were derived from basal sprouts of two mature chestnut trees (P1 and P2) and one adult oak genotype (Sainza). In chestnut, rooting percentage was positively affected by auxin in a dose -dependent manner, particularly in shoots treated with the hormone for $24 \mathrm{~h}$. The effect of auxin on rooting also differed depending on the application method. In shoots treated for $24 \mathrm{~h}$, the highest concentration of auxin produced the healthiest rooted plantlets, in terms of the root system and shoot quality. By contrast, in shoots treated by the basal quick-dip method, the shoot quality was best at the lowest auxin concentration. The effect of urea derivatives on the root system depended on the species as well as on the auxin concentration and application period. Use of the MDPUs improved the root system architecture of auxintreated shoots by promoting lateral root development and triggering the synchronous initiation of root primordia at the base of the shoot. Shoot quality was also improved by MDPUs, which promoted resumption of growth and reduced shoot-tip necrosis.
\end{abstract}

Keywords: Adventitious rooting; auxin; root system; shoot tip necrosis; shoot quality; Urea derivatives

\section{Introduction}

Adventitious rooting (AR) is a complex post-embryogenic process in which roots arise from plant tissues other than the primary root. It is affected by several factors, including the type of explant or tissue, genotype, maturation stage, hormonal balance and nutritional status (Geiss et al. 2009). AR is of a considerable economic importance in the ornamental and forest industries because of the lack of rooting response or/and because poor rooting systems impede the survival of the plants and hinder large-scale propagation of the selected material. In the case of forest tree species, the maturation-related decline in AR competence is a limiting step in the clonal propagation of selected genotypes as their many characteristics or desirable traits are only expressed during the mature phase (Pijut et al. 2011). In Quercus robur L (oak) and 
Castanea sativa (chestnut), efforts have been made over the years to improve the micropropagation and rooting ability of selected mature trees. Successful micropropagation of these species has been achieved by using juvenile-like material, i.e. epicormic shoots, basal and stump sprouts (Vieitez et al. 1985; San-José et al. 1988; Chalupa 1988; Vieitez et al. 1994; Gonçalves et al. 1998; Vidal et al. 2003; Vieitez et al. 2007). By contrast, the rooting ability of crown-derived shoots is very low in both species (Sánchez and Vieitez 1991; Vieitez et al. 1994; Sánchez et al. 1996). Rejuvenation treatments (such as partial etiolation, layering or grafting) improve the reactivity of crown-derived explants of chestnut; however, the rooting ability of rejuvenated shoots remains low (Ballester et al. 1989; Sánchez et al. 1997a). The positive effect on AR in chestnut cuttings after girdling and layering was associated with histological changes in the shoot zones from which roots are formed, as reported by Biricolti et al. (1994).

A basal cut and application of exogenous auxin are essential to induce AR in difficult-to-root species (De Almeida et al. 2015; Steffens and Rasmussen 2016; Gonin et al. 2019). Indole-3butyric acid (IBA) is the most effective and frequently used auxin for inducing AR in cuttings of many species. In chestnut and oak, IBA induces the dedifferentiation of specific cells adjacent to vascular bundles, which undergo a reprogramming process, acquire a new fate and eventually re-enter the cell cycle under a new genetic program. In rooting competent microshoots, these cell types will give rise to root primordia, while in recalcitrant tissues only callus-like structures will be generated (Ballester et al. 2009). Analysis of the endogenous indole-3-acetic acid (AIA) content during early stages of AR in chestnut shoots revealed high AIA levels in auxin-treated shoots as a consequence of the IBA treatment (Gonçalves et al. 2000, 2008). However, the endogenous AIA content of rooting-competent and non-competent shoots of chestnut and oak treated with IBA was not correlated with the maturation-related decline in AR (Ballester et al. 1999; Vidal et al. 2003). In chestnut, the differential response is at least partly a consequence of differences in auxin homeostasis in the tissues; these differences depend on the ontogenetic state and imply differential expression of auxin-responsive genes (Vielba et al. 2011, 2016).

Root development is frequently associated with a callus-like structure originated from cells at the cutting site and that undergo cell division in response to wounding. Moreover, under the same IBA treatment cuttings from mature tissues form callus rather than roots. A balance between the formation of ARs and callus is required because an inverse relationship between the presence of callus formation and rooting has been reported in chestnut (Osterc et al. 2006; Dantas et al. 2016) and other species (Abu-Zabra et al. 2012). Callus formation may also interfere in the establishment of the vascular connection between the root and the stem.

In addition to being affected by auxin, the maturation stage and other factors that regulate rooting, AR competence is a quantitative trait (Riemenschneider 1993) and is thus highly genotype-dependent. Genotypic differences in the rooting ability as well as in the rooting response of shoots to a particular inductive treatment have been reported in chestnut and oak (Dantas et al. 2016; Osterc et al. 2006; Sánchez et al. 1996; Sánchez et al. 1997b).

The standard IBA treatments used in our laboratory to induce AR yield acceptable rooting percentages in juvenile-like microshoots. However, a relatively large number of the plantlets have an unhealthy, fragile appearance and exhibit symptoms of shoot tip necrosis (Vieitez et al. 1986; Sánchez et al. 1996). In addition, the basal dip treatment leads to the formation of many roots along the stem rather than at the base of chestnut microshoots, thus producing a weak root system because the aerial roots are unable to come in contact with the culture medium. Optimization of different factors involved in inductive rooting treatments, such as the auxin 
concentration and mode of application, is therefore key to achieving high rooting percentages and healthy plantlets with a well-developed root system. These plantlets will be more suitable for ex vitro acclimation as they will have a better chance of surviving under ex vitro conditions. In addition, the effect of other compounds that may help to improve the root system and plantlet quality should be tested in order to develop efficient protocols for plant production.

The potential role of urea derivatives on micropropagation has been assessed in several species. Shoot proliferation and shoot regeneration have been improved by the use of thidiazuron (TDZ) and N-phenyl-N,-[6-(2-chlorobenzothiazol)-yl] urea (PBU) in many species (Caglar et al. 2005; Huang et al. 2010; Singh and Dwivedi 2014; Patial et al. 2017) as well as during the induction of somatic embryogenesis and plant regeneration (Khan et al. 2006; Ghosh et al. 2018). PBU has frequently been used in eucalyptus to induce adventitious shoots (Huang et al. 2010; Gosh et al. 2018). In addition, $N, N^{\prime}$-bis-(2,3-methylenedioxyphenyl)urea (2,3MDPU) and $N$ - $N^{\prime}$-bis-(3,4-methylenedioxyphenyl) urea (3,4-MDPU) have been used to induce AR or as adjuvants (Ricci and Bertoletti 2009). Despite their chemical similarity to urea derivatives displaying cytokinin-like activity, these compounds do not show any cytokinin-like or auxin-like activity, although the rooting response was improved in several species, such as apple, pine and caper (Ricci et al. 2001, 2003, 2008; Carra et al. 2012). Both compounds enhanced AR in apple microshoots and Capparis spinosa nodal explants (Ricci et al. 2001; Carra et al. 2012). Use of these compounds in combination with exogenous auxin improved AR in apple stem slices and in Pinus radiata rooting-competent tissues, even at exogenous auxin concentrations that were sub-optimal for $P$. radiata (Ricci et al. 2003, 2008). Although the mode of action of these compounds remains unknown, it has been suggested that they may interact with auxin (endogenous or exogenous) thus improving the rooting response (Ricci and Bertoletti 2009). Furthermore, in Citrus species, these compounds increased the induction of somatic embryogenesis in a species-specific manner (Carra et al. 2006). The positive effects of these compounds on morphogenetic competence suggest that they may indeed modulate the activity of the principal hormones (auxin and cytokinin, respectively) involved in the processes, although the lack of a general effect on the tested species and genotypes makes it difficult to determine the underlying mechanism. Different urea derivatives have direct and indirect effects on endogenous cytokinin metabolism (reviewed in Ricci and Bertoletti 2009).

The objectives of the present study were (1) to determine the best auxin treatment for inducing adventitious rooting in chestnut and oak microshoots and (2) to study the effect of the application of 2,3- and 3,4-MDPU in combination with auxin during adventitious rooting. The findings showed that the MDPUs had a slightly positive effect on the rooting response of microshoots at suboptimal IBA concentrations. Furthermore, the quality of the rooted shoots was improved by the MDPUs. Nonetheless, the success of the MDPU treatment depended on the auxin concentration and method of application and species, in a compound-specific manner. Aspects related to the mode of action of MDPUs are discussed.

\section{Material and methods}

Microshoots derived from basal sprouts of two mature $C$. sativa trees (P1 and $\mathrm{P} 2)$ and one monumental $Q$. robur tree (Sainza) were used in this study. A detailed description of protocols for in vitro establishment and proliferation of these shoot cultures is given elsewhere (Sánchez and Vieitez 1991; Vieitez et al. 1994; Vidal et al. 2003).

\section{Rooting}

For rooting experiments, $2-3 \mathrm{~cm}$ long microshoots were harvested at the end of the proliferation cycle. The callus and basal leaves were removed and the microshoots were placed 
in $300 \mathrm{~mL}$ glass jars containing $50 \mathrm{~mL}$ of basal rooting medium (BRM) consisting of GD medium (Gresshoff and Doy 1972) with macronutrients reduced to one third (GD 1/3) and supplemented with $7 \mathrm{~g} / \mathrm{l}$ of either Difco agar (chestnut) or Vitro agar (oak). All experiments and treatments were performed in three replicate jars, with six microshoots in each (i.e. 18 microshoots per treatment). All experiments were repeated at least twice.

For induction of AR, several treatments with different auxin concentrations and combinations of auxin, MDPUs and application periods were tested. Indole-3-butyric acid (AIB) was the auxin used to induce AR. In chestnut microshoots, the following auxin inductive treatments were performed prior to transfer to BRM: a) "basal quick dip treatment", which consisted of dip-ping the basal end of shoots in a solution of 2450 (low auxin dip) or 4900 (high auxin dip) $\mu \mathrm{M}$ IBA solution for $1 \mathrm{~min}$; b) "24-h treatment" carried out by incubating the shoots in BRM supplemented with 50, 75 or $125 \mu \mathrm{M}$ IBA for $24 \mathrm{~h}$ and c) "5-day treatment", which consisted of incubating the shoots for 5 days in $25 \mu \mathrm{M}$ IBA under dark conditions before transfer to BRM and light conditions. P1 shoots were subjected to the high auxin dip treatment $(4900 \mu \mathrm{M})$ and to the 24 h-IBA treatment. P2 shoots were subjected to the quick dip treatment (2450 and 4900 $\mu \mathrm{M}$ ), to the 24-h treatment with $75 \mu \mathrm{M}$ IBA and to the 5-day treatment. Clones P1 and P2 have previously shown similar rooting responses (Sánchez and Vieitez 1991). In oak microshoots, root induction was performed by the 24 -h treatment with 50,75 or $125 \mu \mathrm{M}$ IBA. The "basal quick dip treatment" was not applied to oak, because preliminary experiments showed a low rooting frequency $(18 \%)$ and unhealthy appearance of the microshoots in response to the treatment (data not shown).

The effect of the MDPUs was evaluated as follows: a) P1 and P2 shoots subjected to quick dip treatment were transferred to BRM supplemented with $0,0.1,1$ or $10 \mu \mathrm{M}$ MDPU $(2,3-$ MDPU or 3,4-MDPU) for $24 \mathrm{~h}$ or for one month; b) the 24-h auxin treatment was conducted in clone P1 (50, 75 and $125 \mu \mathrm{M}$ IBA) in the presence of $0,0.1,1$ or $10 \mu \mathrm{M}$ MDPUs (2,3-MDPU or 3,4-MDPU) and clone P2 (75 $\mu \mathrm{M}$ IBA) in the presence of $0,0.1,1$, or $10 \mu \mathrm{M} 3,4-\mathrm{MDPU}$; and c) the 5-day treatment ( $25 \mu \mathrm{M}$ IBA) was conducted in clone P2 in the presence of $0,0.1,1$ or 10 $\mu \mathrm{M}$ 3,4-MDPU. The effect of the MDPUs on oak microshoots was evaluated as described for chestnut and the 24-h treatment.

At the end of the auxin and auxin plus MDPU treatments, the treated shoots were transferred to BRM for one month or for 25 days, the latter in the case of the 5-day treatment.

\section{Histological analysis}

For histological examination, basal segments $(0.5 \mathrm{~cm})$ were collected from the shoots treated with 2450 or $4900 \mu \mathrm{M}$ IBA for 1 min and supplemented with $0,0.1,1$ or $10 \mu \mathrm{M} 3,4$-MDPU for $24 \mathrm{~h}$. Samples were collected after treatment for 5 days. Four samples were obtained for treatment, and the entire experiment was repeated twice. Histological analysis was performed following the protocol described by Ballester at al. (1999). Briefly, explants were fixed in a mixture of formalin, glacial acetic acid and 50\% ethanol [1:1:18 (v/v/v)], dehydrated through a graded n-butanol series and embedded in paraffin wax. Tissues were sectioned $(10 \mu \mathrm{m})$ on a Reichert-Jung rotatory microtome. Sections were double-stained with safranin-fast green (Jensen 1962). The stained sections were mounted with Euckit ${ }^{\circ}$, and images were captured with an Olympus DP71 digital camera fitted to a Nikon-FXA microscope.

\section{Data collection and statistical analysis}

At the end of the rooting period (1 month), the percentage of rooted shoots, the root number and the length of the longest root were determined. The quality of rooted shoots was assessed 
by the presence of shoot tip necrosis, resumption of shoot growth, basal callus formation and lateral root development. The data presented correspond to 36-54 explants per treatment. The data were analyzed by Levene's test (to verify the homogeneity of variance) and the ShapiroWilk test of normality. The data were then subjected to analysis of variance (ANOVA) followed by comparison of group means (Tukey-b test), or to the Kruskal-Wallis test (when the data were not normally distributed). Statistical analyses were performed using SPSS 25.0 (IBM).

\section{Results}

\section{Effect of IBA treatments on the rooting response}

In order to ascertain the optimal auxin treatment, different concentrations of auxin and periods of application were tested. Within each clone and for the same application period, auxin concentrations were positively correlated with rooting frequency and the number of roots (Table 1). Indeed, in chestnut (P1) microshoots subjected to 24-h IBA treatments, the rooting percentage increased significantly as the IBA concentration increased from 50 to $125 \mu \mathrm{M}$ IBA (Table 1A). Although not statistically significant, the rooting percentage also increased with the IBA concentration in oak shoots (Table 1C). Maximum rooting percentages (94.\% for clone P1 and $80.5 \%$ for oak) were produced in shoots treated with $125 \mu \mathrm{M}$ IBA (Table 1). Moreover, in clone P1 increasing the concentration of IBA from 50 to $125 \mu \mathrm{M}$ not only increased the rooting frequency (from $30.5 \%$ to $94.4 \%$ ) and mean root number (from 2.2 to 5.4 ) $(\mathrm{p} \leq 0.001$ ) but also increased the length of the longest root (from 29.0 to $39.8 \mathrm{~mm}$ ) (Table 1, Fig. 1A). By contrast, the auxin concentration did not significantly affect those parameters in oak. However, the highest rooting percentages and the number of roots were achieved with the $125 \mu \mathrm{M}$ IBA treatment.

In clone P1, similar rooting percentages were achieved with the high auxin dip (4900 $\mu \mathrm{M}$ IBA) and the 24-h (125 $\mu \mathrm{M}$ IBA) treatments (Table 1). The high auxin dip treatment produced the greatest number of roots in both chestnut clones (6.6 in P1 and 7.9 in P2; Table 1). In clone $\mathrm{P} 2$, the number of roots decreased significantly $(\mathrm{p} \leq 0.05)$ as the concentration of the auxin dip decreased (Table 1B, Fig. 1B). The basal dip treatment stimulated callus formation at the basal end of the shoot and also development of adventitious roots from the lower half of the shoot rather than from the callus itself (Figs. 1B, 8A). Formation of ARs further from the basal callus was also promoted by the high auxin dip $(4900 \mu \mathrm{M}$ IBA; Fig. 1B). Moreover, the latter treatment caused a high level of shoot tip necrosis, probably due to the supra-optimal levels of auxin. The response of P1 shoots to the quick auxin dip was similar to that previously described in $\mathrm{P} 2$ shoots (data not shown).

In clone $\mathrm{P} 2$ the best rooting responses, in terms of rooting percentage, root length and lateral root development, were obtained with the 5-day IBA treatment $(25 \mu \mathrm{M})$ (Table 1, Fig. 1C). The root number achieved with this treatment (5.4) was significantly higher $(\mathrm{p} \leq 0.05)$ than that obtained in shoots treated for $24 \mathrm{~h}$ with $75 \mu \mathrm{M}$ IBA (3.0). In terms of shoot and root quality, the 24-h and 5-day IBA treatments with $125 \mu \mathrm{M}$ and $25 \mu \mathrm{M}$, respectively, produced better results than the basal quick dip with high IBA concentrations (Fig. 1A, C).

\section{Effect of MDPUs on adventitious rooting of chestnut and oak microshoots}

The effects of 2,3- and 3,4-MDPU were first tested in chestnut shoots subjected to the 24-h auxin treatment. P1 shoots were treated with 50,75 or $125 \mu \mathrm{M}$ IBA for $24 \mathrm{~h}$ in the presence of $0,0.1,1$ and $10 \mu \mathrm{M}$ 2,3-MDPU and 3,4-MDPU. The effect of 3,4-MDPU was evaluated in P2 
shoots treated with $75 \mu \mathrm{M}$ IBA. Although rooting parameters were not significantly affected by the presence of MDPUs, the rooting percentage increased two-fold in the presence of $0.1 \mu \mathrm{M}$ 2,3-MDPU at suboptimal concentration of IBA (Fig. 2A). Moreover, this compound slightly improved lateral root development in an auxin concentration-dependent manner (Fig. 3). As the concentration of exogenous auxin was increased (to $125 \mu \mathrm{M}$ ), the concentration of 2,3-MDPU required to improve the root system decreased (Fig. 3C).

Treatment of shoots with IBA plus 3,4-MDPU exerted a strong positive effect on promoting lateral roots in shoots (Figs. 4 and 5), although the rooting frequency was not significantly affected $(p \geq 0.7)$ at the auxin concentrations tested (Fig. 2B). In addition, the quality of shoots in rooted plantlets was greatly improved in shoots subjected to the 5-day IBA treatment plus 3,4-MDPU (Fig. 5). Shoot tip necrosis was reduced as the concentration of the MDPU increased, whereas resumption of new growth increased gradually and significantly in response to the presence of 3,4-MDPU (Table 2 and Fig. 5). Furthermore, the presence of 3,4-MDPU promoted initiation of roots at the base of the shoot. Callus formation was observed in $83.3 \%$ of rooted plantlets in the 5-day IBA treatment, but in only $38.8 \%$ of rooted plantlets when the auxin inductive treatment was performed in the presence of all concentrations of 3,4-MDPU tested. On the other hand, a rooting frequency of $100 \%$ was achieved in the presence 3,4MDPU.

The effect of the MDPUs on AR was also evaluated in oak shoots subjected to the 24-h auxin treatments. MDPU did not significantly affect the rooting percentage in IBA treatments $(\mathrm{p}$ values ranged from $\leq 0.11$ to 0.83 ), the number of roots ( $p$ values ranged from $\leq 0.12$ to 0.51 ) or the length of the longest root ( $\mathrm{p}$ values ranged from $\leq 0.1$ to 0.98 ). Regarding each specific IBA treatment, the greatest increase in rooting frequency was observed when roots were induced in the presence of $75 \mu \mathrm{M}$ IBA plus $0.1 \mu \mathrm{M}$ of 3,4-MDPU (86.9\%) relative to the IBA treatment alone $(68.1 \%)$. On the other hand, no such increase was not observed in the presence of 2,3MDPU.

The most notable effect of MDPUs on oak rooting was the improvement in plantlet quality. In line with the above results described in chestnut, shoots treated with IBA plus MDPUs were healthier than those treated with IBA alone. Regardless of the compound, the presence of MDPUs during the auxin induction period promoted the growth of the shoot apex at all concentrations tested (Fig. 6, Table 3). Plantlets rooted in the presence of MDPUs were taller due to resumption of shoot growth, which was clearly detected by the normal green color in contrast to the pale green appearance of the initial explant.

The effect on AR of the presence of the MDPUs and the period application was also explored in chestnut microshoots subjected to the quick dip treatment. Auxin-treated shoots (P1 and P2) were incubated for $24 \mathrm{~h}$ or one month in BRM supplemented or not with MDPUs. Regardless of the treatment, rooting percentage was not significantly affected by the presence of MDPUs (Fig. 7), although slight differences were observed depending on which MDPU compound was used. Continuous exposure of shoots to 2,3-MDPU promoted initiation of roots at the shoot base and lateral root development (Fig. 8). These beneficial effects, particularly the increase in the number and length of the lateral roots, were also observed in shoots treated with 3,4-MDPU for only $24 \mathrm{~h}$ (Fig. 9). In general, the low auxin dip $(2450 \mu \mathrm{M}$; Fig. 9A) produced healthier shoots but fewer roots than the high auxin $\operatorname{dip}(4900 \mu \mathrm{M}$; Fig. 9B). As previously described for the 24 h-IBA treatments, the shoot quality of rooted shoots was always improved by the presence of MDPUs. 
Figure 10 shows the results of the histological study carried out to evaluate at the cellular level the effect of the presence of 3,4-MDPU on the initiation of adventitious roots. Root formation in chestnut occurred as previously described by Ballester et al. (1999). First cell divisions leading to the root primordia took place in the cambium and the adjacent phloem cells. On day 5, meristemoids and root primordia were observed in shoots treated with IBA as well as in shoots treated with IBA plus 3,4-MDPU. However, in root initials cell division appeared to occur earlier in the presence of 3,4-MDPU, as more advanced and larger root primordia were observed relative to control sections (Fig. 10A-D). Examination of serial sections taken at the same distance from the basal callus (1000-1200 $\mu \mathrm{m}$ above the base of the shoot) revealed that the number of root primordia visible in sections from IBA treated shoots was about half (Fig. 10A) that observed in shoots treated with the highest concentration of 3,4-MDPU (Fig. 10C). 3,4-MDPU therefore promotes more synchronous rooting, which takes place at the basal part of the shoot. Root primordia initiated at the basal end of the shoot were only observed in sections of shoots treated with IBA plus 3,4-MDPU. The activity of MDPUs in initiating roots at the shoot base was also evident when shoots were rooted in the continuous presence of 2,3-MDPU (Fig. 8). The root system archiecture thus appears to be modulated by the presence of MDPUs.

\section{Discussion}

The rooting stage is the main bottleneck in the clonal propagation of selected genotypes, either by cuttings or by in vitro culture, particularly in tree species recalcitrant to forming roots. Establishing the optimal conditions for inducing ARs is an important step in propagation methods and research protocols. In addition, a significant loss of plants produced by tissue culture occurs at the acclimatization stage. Therefore, to obtain high survival rates during acclimatization it is essential to produce a number of vigorous plantlets with a well-developed root system.

In order to improve the rooting responses in chestnut and oak microshoots, in terms of rooting percentage, root system and plant quality, we first analyzed the effect of auxin concentration and application method. High rooting percentages were achieved in the two species by modulating these factors (Table 1). Two common strategies are used to induce AR in microshoots: a high auxin concentration for a few seconds (5-60 s), and a lower concentration for a longer period (few hours to several days). In chestnut, rooting percentages in juvenile-like P2 shoots achieved using the auxin dip treatment were similar to those previously reported by Sánchez and Vieitez (1991) for the same treatment, indicating a very stable feature in this clone through almost three decades of in vitro culture. Basal dip treatments with two concentrations of IBA have been used for rooting different genotypes of American chestnut microcuttings (Xing et al. 1997). These authors concluded that the concentration of IBA should be optimized for each genotype.

In our study there were no differences in rooting frequency in the two clones of chestnut in response to the same IBA treatment (dipping or $24 \mathrm{~h} / 75 \mu \mathrm{M}$, Table I A-B). These data are consistent with previous results achieved during the induction of ARs in both clones (Sánchez and Vieitez 1991). Donor trees (80 years old) of clones P1 and P2 were derived from seeds and located in the same natural population, at a short distance from each other $(6 \mathrm{~m})$. The similar rooting responses of microshoots initiated from these trees suggest a close genotypic relationship, at least for the rooting competence trait. By contrast, the rooting responses of several clones of chestnut reported by Sánchez et al. (1997b) were lower than obtained in clones P1 and P2 for the same treatment. These differences are probably a consequence of the genotype effect on the rooting ability (Bonga 1987). The effect of the genotype on rooting performance of 
microshoots has previously been documented in oak and american chestnut (Vieitez et al. 1994; Xing et al. 1997).

Several studies have shown that excess auxin can have a detrimental effect on the rooting frequency or the number of roots obtained. For instance, the application of $15 \mu \mathrm{M}$ IBA for 3 days was the best treatment for root induction in peach, whereas higher concentrations of hormone and longer exposure times produced a lower rooting percentage and induced the formation of more callus (Park et al. 2017). Indeed, long exposure to hormones can have a negative effect, as auxins inhibit the initiation phase of the rooting process (De Klerk et al. 1999). In peach, cuttings failed to root at IBA concentrations higher than $1250 \mu \mathrm{M}$, which may have been a consequence of the duration of the application period (Tworkosky and Takeda 2007). Basal dipping of persimmon cuttings with $10 \mathrm{mM}$ produced the highest rooting frequency, whereas number of roots increased with increasing IBA concentrations up to $25 \mathrm{mM}$ (Hejazi et al. 2018). Similarly, the number of roots was increased by increasing the IBA concentration in the quick auxin dip method, but this treatment reduced the longest root length (Table 1B).

High auxin concentration may be detrimental to plantlet quality, by promoting root formation along the stem and shoot tip necrosis. In chestnut, shoot tip necrosis has been reduced by the localized application of cytokinin during the rooting period or by including the cytokinin in the rooting medium (Vieitez et al. 1989; Xing et al. 1997). Moreover, the addition of ascorbic acid to the rooting medium improved the quality of rooted plantlets and reduced shoot tip necrosis (Lê 2001). In chestnut, the method of auxin application seems to be important for obtaining healthy plantlets that survive after transfer to soil. Relatively low IBA concentrations for an extended application period ( 5 days) produced the best results in terms of rooting percentage and plantlet quality. For the 24-h IBA treatment, rooting parameters were positively affected by auxin in a dose-dependent manner in chestnut, but not in oak (Table 1), indicating a speciesdependent effect of IBA concentration on AR. A positive effect of auxin concentration on AR was also observed in red oak (Sánchez et al. 1996). On the other hand, the highest rooting percentage induced in oak by $125 \mu \mathrm{M}$ IBA was similar to that reported by Vidal et al. (2003) for the same clone and treatment. The rooting ability of the oak clone has therefore been kept stable for almost two decades of in vitro culture.

On the basis of our results, and regardless of the application method, rooting percentage generally increased with increasing IBA concentration (Table 1). Similarly, a strong relationship has been observed between the concentration of auxin and rooting frequency in cuttings of Azadiratcha indica (Gehlot et al. 2014). However, the auxin application method is also important because it affected the rooting response and the quality of the rooted plantlets. Nonetheless, a balance must be established between the improvement in rooting frequency and the health status of the microshoots. The use of sub-optimal IBA treatments provided us with the opportunity to examine the putative effects of MDPUs on rooting.

$\mathrm{AR}$ is a developmental program divided into three major phases, i.e. induction, initiation and expression, each of which has specific hormonal requirements (De Klerk et al. 1999; Bellini et al. 2014; reviewed in Geiss et al. 2009). Nonetheless, in recalcitrant forest species an additional dedifferentiation step (sometimes called activation) is generally included at the early steps of the rooting process. This involves a switch in the identity of initial cells, which become capable of responding to exogenous stimuli in a root developmental pathway (Abarca and Díaz-Sala 2009). Although auxins are known to be master regulators of this process, several hormones influence the process through their own activity and their interactions with auxin, generating a complex hormonal crosstalk that impacts homeostasis and signalling of the hormones involved (Lakehal 
and Bellini 2019). Cytokinin, a known inhibitor of AR and lateral root development (Steffens and Rasmussen 2016; Jing and Strader 2019), interacts at many levels with auxin depending on the tissue and context in which they are located (Chandler and Werr 2015).

Urea derivatives have been described as rooting adjuvants as they enhance adventitious root formation in mung bean shoots and apple microshoots (Ricci et al. 2006). Root formation on stem slices of apple was enhanced when roots were induced in the presence of 2,3-MDPU and 3,4-MDPU in combination with suboptimal IBA concentrations (Ricci et al. 2003). The effect of MDPUs on AR in oak and chestnut was thus tested in combination with different auxin concentrations.

In our experimental systems, these compounds did not enhance the rooting percentage in shoots treated with IBA alone, but improved the general appearance of rooted shoots. Furthermore, MDPUs promoted the initiation of ARs at the cutting site, particularly in shoots treated by basal dipping in IBA. Auxin-responsive cells are generally located in the cambial and vascular tissues and are capable of generating root primordia at the shoot base as well as along the shoot stem (Fig. 1B). The presence of ARs in the upper part of the IBA-treated shoots indicates that the auxin stimulus has reached those cells. On the other hand, the effect of MDPUs promoting the initiation of ARs at the base of IBA-treated microshoots (Fig. 8 and 9) suggests that their activity is linked to the auxin transport machinery and the auxin/cytokinin interaction. It is possible that MDPUs act by modulating exogenous auxin transport, but without perturbing the basipetal transport of endogenous auxin from the leaves and buds towards the base of the stem. The putative role of other urea derivatives during AR has been related to the auxin gradients or auxin distribution in specific cells from which root primordia originate, preventing callus formation (Brunoni et al. 2014). However, the effect of urea derivatives on rooting seems to be highly dependent on the dose of the compound as well as the concentration of auxin.

The presence of MDPUs reduced the symptoms of shoot tip necrosis and promoted resumption of growth, the latter particularly in the oak shoots (Table 3, Figs. 5 and 6). In apple, shoot tip necrosis has been associated with low levels of endogenous hormones (Kataeva et al. 1991). Moreover, the incidence of shoot tip necrosis seems to be related to the transport and inner distribution of cytokinins (Bairu et al. 2011). Urea derivatives may therefore influence auxin/cytokinin cross-talk through their transport machineries, enabling auxin to reach maximum levels at the root initial cells and at the same time facilitating cytokinin transport towards the apex by a transport system that is not yet completely defined (Durán-Medina et al. 2017). In fact, callus-like structures generated during in vitro rooting are considered cytokinin sinks (Viéitez et al. 1989).

In the present study, the effect of the urea derivatives varied according to the urea derivative, the auxin concentration and the tree species considered. Different auxins applied for different lengths of time can have drastically different effects on the in vitro rooting performance of the explants. For instance, Tereso et al. (2008) reported contrasting results for rooting percentages produced in response to different auxins and different exposure times in almond shoots. As observed in Arabidopsis hypocotyls, changes in the auxin concentration also affect callus formation (Da Costa et al. 2018). The auxin responsive machinery has the potential to confer quantitatively different responses to varying auxin concentrations and to different auxins (Weijers and Wagner 2016). Our results showed that the effects of auxin concentration on rooting responses were modulated differently by the two MDPUs depending on the treatments. 
Overall the results showed that MDPUs improved the quality of rooted plantlets, promoted development of the lateral root system and may prevent formation of basal callus (Figs. 5, 6 and 9). Regardless of the application period ( $24 \mathrm{~h}, 5$ days or one month), MDPU treatments induced the formation of a greater number of lateral roots on adventitious roots in chestnut microshoots (Figs. 4, 5 and 8). The presence of more lateral roots indicates improved auxin transport in the new generated roots, again indicating the putative effect of MDPUs on auxin transport. An improved root system with many lateral roots and without callus formation was reported during AR of Capparis spinosa microcuttings in the presence of auxin and 2,3-MDPU and 3,4-MDPU (Carra et al. 2012). In chestnut, callus formation at the shoot base was reduced at high concentrations $(1-10 \mu \mathrm{M})$ of MDPUs, but the effect was dependent on the auxin concentration. Although callus formation was negatively correlated with rooting percentage in chestnut and other species (Dantas et al. 2016), in the experimental system used here the presence of callus did not have a detrimental effect on rooting percentage.

In chestnut microshoots, MDPUs induced early cell divisions in root initials in IBA-treated shoots, during the first $24 \mathrm{~h}$ when first cell divisions occurred in response to auxin (Ballester et al. 1999; Vidal et al. 2003). Inhibition of callus formation on the shoots treated with MDPUs probably takes place within the same time frame. Callus formation is a common response to wounding in plant tissues, and it often occurs simultaneously to AR (Steffens and Rasmussen 2016). Moreover, in Arabidopsis, the initial stages of callus formation recapitulate the same steps as lateral root formation (reviewed in Sugimoto et al. 2011). Thus, it appears that auxin induction triggers both developmental programs but that MDPU activity promotes the AR program to displace the callus program, probably by restricting the auxin response within specific cells. Ricci et al. (2016) reported the dual morphogenetic role (adventitious root formation or xylogenesis) of urea derivatives, depending on the presence of auxin (Ricci et al. 2016). In addition, MDPUs induce localized areas of cell divisions in IBA-treated pine cuttings (Ricci et al. 2008), which is consistent with the observations in chestnut microshoots (Fig. 10).

In conclusion, in vitro rooting of chestnut and oak microshoots was optimized by treating the shoots with $25 \mu \mathrm{M}$ IBA for 5 days or with $125 \mu \mathrm{M}$ IBA for $24 \mathrm{~h}$, respectively. Urea derivative treatments improved the rooting response in chestnut and oak microshoots in different ways that depended on the auxin treatment and the tree species. Major effects were the improved quality of the root system due to the synchronous initiation of root primordia at the shoot base and a more developed lateral root system. Resumption of growth of the oak microshoots indicated the positive effect of MDPUs on the overall health status of the plantlets. We believe that the mode of action of these urea derivatives is related to the auxin transport machinery and probably to improved endogenous cytokinin homeostasis in the shoots.

Acknowledgments: This work was partially funded by the Xunta de Galicia through the Contrato Programa 2016-2018 and the project IN607A 2017/6.

\section{References}

Abarca, D., Díaz-Sala, C. (2009). Reprogramming adult cells during organ regeneration in forest species. Plant Signal. Behav. 4(8): 793-795. DOI: 10.4161/psb.4.8.9238.

Abu-Zabra, T.R., Hasan, M.K., Hasan, H.S. (2012). Effect of different auxin concentrations on Virginia Creeper (Parthenocissus quinquefolia) rooting. World Appl. Sci. J. 16: 07-10. 
Bairu, M.W., Novák, O., Doležal, K., van Staden, J. (2011). Changes in endogenous cytokinin profiles in micropropagated Harp-agophytum procumbens in relation to shoot-tip necrosis and cytokinin treatments. Plant Growth Regul. 63: 105-114. DOI: 10.1007/s10725-010-9558-6.

Ballester, A., Sanchez, M.C., Vieitez, A. (1989). Etiolation as a pretreatment for in vitro establishment and multiplication of mature chestnut. Physiol. Plant.77: 395-400.

Ballester, A., San-José, M.C., Vidal, N., Fernández-Lorenzo, J.L., Vieitez, A.M. (1999). Anatomical and biochemical events during in vitro rooting of microcuttings from juvenile and mature phases of chestnut. Ann. Bot. 83: 619-629. DOI: 10.1006/ anbo.1999.0865.

Ballester, A., Vidal, N., Vieitez, A.M. (2009). Developmental stages during in vitro rooting of harwood trees from material with juvenile and mature characteristics. In: A. Niemi and K. And Scagel, C., eds., Adventitious root formation of forest trees and horticultural plants-from genes to applications. Kerala: Research Signpost, pp. 277-296.

Bellini, C., Pacurar, D., I. Perrone (2014). Adventitious Roots and Lateral Roots: Similarities and Differences. Annual Review of Plant Biology. 65(1): 639-666. DOI: 10.1146/annurev -arplant050213-035645.

Biricolti, S., Fabbri, A., Ferrini, F., Pisani, P.L. (1994) Adventitious rooting in chestnut: and anatomical investigation. Sci. Hortic. 59:197-205.

Bonga, J.M. (1987). Clonal propagation of mature trees: problems and possible solutions. In: J.M. Bonga and D.J. Durzan, eds., Cell and Tissue Culture in Forestry. Dordrecht: Martinus Nijhoff Publishers, pp. 249-271. DOI: 10.1007/978-94-017-0994-1_15.

Brunoni, F., Rolli, E., Dramis, L., Incerti, M., Abarca, D., Pizar-ro, A., Diaz-Sala, C., Ricci, A. (2014). Adventitious rooting -adjuvant activity of 1,3-di(benzo[d]oxazol-5-yl)urea and 1,3-di(benzo[d]oxazol6-yl)urea: New insights and perspectives. Plant Cell. Tissue Organ Cult. 118: 111-124. DOI: 10.1007/s11240-014-0466-8.

Caglar G., Caglar, S., Erguin, O. Yarim, M. (2005). The influence of growth regulators on shoot proliferation and rooting of in vitro propagated caper. J. Envirom. Biol. 26:479-485.

Carra, A., De Pasquale, F., Ricci, A., Carimi, F. (2006). Diphenyl-urea derivatives induce somatic embryogenesis in Citrus. Plant Cell. Tissue Organ Cult. 87: 41-48. DOI: 10.1007/ s11240-006-91320 .

Carra, A., Del Signore, M.B., Sottile, F., Ricci, A., Carimi, F. (2012). Potential use of new diphenylurea derivatives in micropropagation of Capparis spinosa L. Plant Growth Regul. 66: 229- 237. DOI: 10.1007/s10725-011-9645-3.

Chalupa, V. (1988). Large scale micropropagation of Quercus robur L. using adenine-type cytokinins and thidiazuron to stimulate shoot proliferation. Biol. Plant. 30: 414-421. DOI: 10.1007/BF02890509.

Chandler, J.W., Werr, W. (2015). Cytokinin-auxin crosstalk in cell type specification. Trends Plant Sci. 20(5): 291-300. DOI: 10.1016/j.tplants.2015.02.003.

Da Costa, C.T., Gaeta, M.L., Ernesto, D.A., et al. (2018). Comparative adventitious root development in pre-etiolated and flooded Arabidopsis hypocotyls exposed to different auxins. Plant Physiol. Biochem. 127:161-168. DOI: 10.1016/j. plaphy.2018.03.022.

Dantas, Â.K., Majada, J., Dantas, F.K., Delatorre, C., Granda, V., Vallejo, P., Feito, I. (2016). Rooting of Minicuttings of Castanea sativa Mill. Hybrid clones. Revista Árvore, Viçosa-MG, 40: 465-475. DOI: 10.1590/0100-67622016000300010.

De Almeida, M.R., Bastiani, D., Gaeta, M.L., Mariath, J.E.A., De Costa, F., Retallick, J., et al. (2015). Comparative transcriptional analysis provides insights into the molecular basis of adventitious rooting recalcitrance in Eucalyptus. Plant Sci. 239: 155-165. DOI: 10.1016/j.plantsci.2015.07.022.

De Klerk, G.J., Van der Krieken, W., de Jong, J.C. (1999). The formation of adventitious roots: new concepts, new possibilities. In Vitro Cell. Dev. Biol. Plant. 35: 189-199. DOI: 10.1007/s11627-9990076-z.

Duran-Medina, Y., Diaz-Ramirez, D., Marsch-Martinez, N. (2017). Cytokinins on the Move. Front. Plant Sci. 8: 146. DOI: 10.3389/ fpls.2017.00146. 
Gehlot, A., Gupta, R.K., Arya, I.D., Arya, S., Tripathi, A. (2014). De novo Adventitious Root Formations (ARF) in mini-cuttings of Azadirachta indica in response to different rooting media and auxin treatments. iForest 8: 558-564. DOI: 10.3832/ ifor1189-007.

Geiss, G., Gutierrez, L., Bellini, C. (2009). Adventitious Root Formation: New Insights and Perspectives. In: Beeckman, T., ed., Annual Plant Reviews - Root Development. Wiley-Blackwell, 37: 127-156. DOI: 10.1002/9781119312994.apr0400.

Ghosh, A., Igamberdiev, A.U., Debnath, S.C. (2018). Thidiazuron-induced somatic embryogenesis and changes of antioxidant properties in tissue cultures of half-high blueberry plants. Sci. Rep. 8:16978. DOI: $10.1038 / \mathrm{s} 41598-018-35233-6$.

Gresshoff, P.M., Doy, C.H. (1972). Development and differentiation of haploid Lycopersicon esculentum. Planta 107: 161- 170. DOI: 10.1007/BF00387721.

Gonçalves, J.C., Diogo, G., Amancio, S. (1998). In vitro propagation of chestnut (Castanea sativa x $C$. crenata): Effects of rooting treatments on plant survival, peroxidase activity and anatomical changes during adventitious root formation. Sci. Hortic. 72: 265-275.

Gonçalves, J.C., Diogo, G., Coelho, M.T., N. Vidal, Amâncio, S. (2000). Adventitious rooting in microshoots of chestnut hybrid (Castanea sativa x $C$. crenata) in the presence of indole-3-butyric acid: The role of changes in endogenous indole-3-acetic acid, indole-3-acetylaspartic acid and indole3-butyric acid levels. In: Book of Abstracts: Third Symposium on Adventitious Root Formation. The Netherlands: Veldhoven, pp. 1-8.

Gonçalves, J.C., Diogo, G., Coelho, M.T., N. Vidal, Amâncio, S. (2008). Quantitation of endogenous levels of IAA, IAAsp and IBA in micropropagated shoots of hybrid chestnut pretreated with IBA. In Vitro Cell. Dev. Biol.-Plant 44:412-418. DOI 10.1007/s11627-008-9151-0.

Gonin, M., Bergougnoux, V., Nguyen, T.D., Gantet, P., A. Champion (2019). What Makes Adventitious Roots?. Plants 8:240. DOI:10.3390/plants8070240.

Hejazi, Z., Ishimura, S., Honsho, C., T. Tetsumura (2018). Effect of planting time, irrigation system, rooting media and IBA concentration on cutting propagation of the persimmon dwarfing rootstock 'MKR1'. Hort. J. 87(2): 184-192. DOI: 10.2503/ hortj.OKD-125.

Huang, Z.C., F.H. Zengh, X.Y. Lu (2010) Efficient regeneration of Eucalyptus urophylla from seedlingderived hypocotyls. Biol. Plant. 54 (1): 131-134.

Jensen, W.A. (1962). Botanical histochemistry: principles and practice. W.H. Freeman, San Francisco, CA (USA) 408 p.

Jing, H., Strader, L.C. (2019). Interplay of auxin and cytokinin in lateral root development. Int. J. Mol. Sci. 20: 486. DOI: 10.3390/ijŠms20030486.

Kataeva, N.V., Alexandrova, I.G:, Butenko, R.G., Dragavtceva, E.V. (1991). Effect of applied and internal hormones on vitrification and apical necrosis of different plants cultured in vitro. Plant Cell, Tissue and Organ Cult. 27: 149-154.

Khan, H., Siddique, I., Anis, M. (2006). Thidiazuron induced somatic embryogenesis and plant regeneration in Capsicum anuum. Biol. Plant. 50: 789-792. DOI: 10.1007/s10535-006-0133-y.

Lakehal, A., Bellini, C. (2019). Control of adventitious root formation: insights into synergistic and antagonistic hormonal interactions. Physiol. Plant. 165: 90-100. DOI: 10.1111/ ppl.12823.

Lê C. (2001). Factors inflencing in vitro rooting of chestnut. For. Snow Landsc. Res. 76 (3): $468-471$.

Osterc, G., Štefančič, M., Solar, A., A. Štampar (2006). The effect of severance date and rooting ability of chestnut cuttings in associated changes in phenolic content during adventitious root formation. Phyton, 46: 285-294.

Park, S.H., Elhiti, M., Wang, H., Xu, A., Brown, D., Wang, A. (2017). Adventitious root formation of in vitro peach shoots is regulated by auxin and ethylene. Sci. Hortic. 226: 250-260. DOI: 10.1016/j.scienta.2017.08.053.

Patial, V., M. Sharma, Bhattacharya, A. (2017) Potential of thidiazuron in improved micropropagation of Picrorhiza kurroa - an endangered medicinal herb of alpine -Himalaya, Plant Biosystems - An 
International Journal Dealing with all Aspects of Plant Biology, 151:4, 729-736, DOI: 10.1080/11263504.2016.1219417.

Ricci, A., Bertoletti, C. (2009). Urea derivatives on the move: cytokinin- like activity and adventitious rooting enhancement dependent on chemical structure. Plant Biology 11: 262-272. DOI: 10.1111/j.1438-8677.2008.00165.x.

Ricci, A., Carra, A., Rolli, E., Bertoletti, C., Branca, C. (2003). N,N,-bis-(2,3-methylenedioxyphenyl)urea and N,N,-bis-(3,4-meth-ylenedioxyphenyl)urea interact with auxin in enhancing root formation of M26 apple (Malus pumila Mill.) stem slices. Plant Growth Regul. 40: 207-212. DOI: 10.1023/A:1025045213739.

Ricci, A., Carra, A., Torelli, A., Maggiali, C.A., Morini, G., Branca, C. (2001). Cytokinin-like activity of $\mathrm{N}, \mathrm{N},-$ diphenylureas. N,N,-bis-(2,3-methylenedioxyphenyl)urea and N,N,-bis-(3,4-methylenedioxyphenyl)urea enhance adventitious root formation in apple rootstock M26 (Malus pumila Mill.). Plant Sci. 160: 1055-1065. DOI: 10.1016/S0168-9452(01)00359-4.

Ricci, A., Rolli, E., Dramis, L., Diaz-Sala, C. (2008). N,N,-bis-(2, 3 Methylenedioxyphenyl)urea and N,N-,bis-(3,4methyl- enedioxyphenyl)urea enhance adventitious rooting in Pinus radiata and affect expression of genes induced during adventitious rooting in the presence of exogenous auxin. Plant Sci. 175(3): 356-363. DOI: 10.1016/j.plantsci.2008.05.009.

Ricci, A., Rolli, E., Brunoni, F., Dramis, L., Sacco, E., Fattorini, L. et al. (2016). 1,3-di(benzo[d]oxazol5 -yl)urea acts as either adventitious rooting adjuvant or xylogenesis enhancer in carob and pine microcuttings depending on the presence/absence of exogenous indole-3-butyric acid. Plant Cell Tiss. Organ Cult. (2016) 126:411-427. DOI 10.1007/s11240-016-1010-9.

Riemenschneider, D.E. (1993) Genomic manipulation of plant materials or adventitious rooting research. In: T.D. Davis and B.E. Haissig eds., Biology of adventitious root formation. New York: Plenum, pp. 61-76.

San-José, M.C., Ballester, A., Vieitez, A.M. (1988). Factors affecting in vitro propagation of Quercus robur L. Tree Physiol. 4: 281-290. DOI: 10.1093/treephys/4.3.281.

Sánchez, M.C., Ballester, A., Vieitez, A. (1997a). Reinvigoration treatments for the micropropagation of mature chestnut trees. Ann. Sci. For. 54: 359-370.

Sánchez, M.C., San-José, M.C., Ballester, A., Vieitez, A.M. (1996). Requirements for in vitro rooting of Quercus robur and Q. rubra shoots derived from mature trees. Tree Physiol. 16: 673- 680. DOI: 10.1093/treephys/16.8.673.

Sánchez, M.C., San-José, M.C., Ferro, E., Ballester, A., Vieitez, A.M. (1997b). Improving micropropagation conditions for adult-phase shoots of chestnut. J. Hortic. Sci. 72: 433-443. DOI: 10.1080/14620316.1997.11515531.

Sánchez, M.C., Vieitez, A.M. (1991). In vitro morphogenetic competence of basal sprouts and crown branches of mature chestnut. Tree Physiol. 8: 59-70. DOI: 10.1093/treephys/8.1.59.

Steffens, B., Rasmussen, A. (2016). The Physiology of Adventitious Roots. Plant Physiol. 170: 603-617. DOI: $10.1104 /$ pp.15.01360.

Singh, P., Dwivedi, P. (2014). Two-stage culture procedure using thidiazuron for efficient micropropagation of Stevia rebaudiana, an anti-diabetic medicinal herb. Biotech. 4 (4):431-437. DOI:10.1007/s13205-013-0172-y.

Sugimoto, K., Gordon, S.P., E.M. Meyerowitz (2011). Regeneration in plants and animals: dedifferentiation, transdifferentiation, or just differentiation? Trends Cell Biol. 21: 212-218. DOI: 10.1016/j.tcb.2010.12.004.

Tereso, S., Miguel, C.M., Mascarenhas, M., Roque, A., Trindade, H., Maroco, J., Oliveira, M.M. (2008). Improved in vitro rooting of Prunus dulcis Mill. Cultivars. Biol. Plant 52: 437-444. DOI: 10.1007/s10535-008-0088-2. 
Tworkoski, T., Takeda, F. (2007). Rooting response of shoot cuttings from three peach growth habits. Sci. Hortic. 115: 98- 100. DOI: 10.1016/j.scienta.2007.08.004.

Vidal, N., Arellano, G., San-José, M.C., Vieitez, A., Ballester, A. (2003). Developmental stages during the rooting of in-vitro-cultured Quercus robur shoots from material of juvenile and mature origin. Tree Physiol. 23: 1247-1254. DOI: 10.1093/ treephys/23.18.1247.

Vieitez, A.M., San-José, M.C., Vieitez, E. (1985). In vitro plantlet regeneration from juvenile and mature Quercus robur L. J Hort Sci 60: 99-106. DOI: 10.1080/14620316.1985.11515607.

Vieitez, A.M., Sánchez, M.C., J.B. Amo-Marco, Ballester, A. (1994). Forced flushing of branch segments as a method for obtaining reactive explants of mature Quercus robur trees for micropropagation. Plant Cell Tissue Organ Cult. 37: 287-295. DOI: 10.1007/BF00042342.

Vieitez, A.M., Sánchez, M.C., García-Nimo, M.L., Ballester, A. (2007). Protocol for micropropagation of Castanea sativa. In: Protocols for Micropropagation of Woody Trees and Fruits. Jain, S.M. and Hägmann, H. (eds). Springer, Dordrecht. 299-312. DOI: 10.1007/978-1-4020-6352-7_28.

Vieitez, A.M., Sánchez, C., San-José, M.C. (1989). Prevention of shoot-tip necrosis in shoot cultures of chestnut and oak. Sci. Hortic. 41: 151-159. DOI: 10.1016/0304-4238(89)90059-9.

Vielba, J.M., Díaz-Sala, C., Ferro, E., Rico, S., Lamprecht, M., Abarca, D., Ballester, A., Sánchez, C. (2011). CsSCL1 is differentially regulated upon maturation in chestnut microshoots and is specifically expressed in rooting-competent cells. Tree Physiol. 31(10): 1152-1160. DOI: 10.1093/treephys/tpr086.

Vielba, J.M., Varas, E., Rico, S., Covelo, P., Sánchez, C. (2016). Auxin-mediated expression of a GH3 gene in relation to ontogenic state in Chestnut. Trees - Struct. Funct. 30(6): 2237-2252. DOI: 10.1007/s00468-016-1449-7.

Weijers, D., Wagner, D. (2016). Transcriptional Responses to the Auxin Hormone. Annu. Rev. Plant Biol. 67: 539-574. DOI: 10.1146/annurev-arplant-043015-112122.

Xing, Z., M.F. Satchwell, Powel, W.A., C.A. Maynard (1997). Micropropagation of American chestnut: increasing rooting rate and preventing shoot-tip necrosis. In Vitro Cell. Dev. Biol.-Plant 33:43-48. 

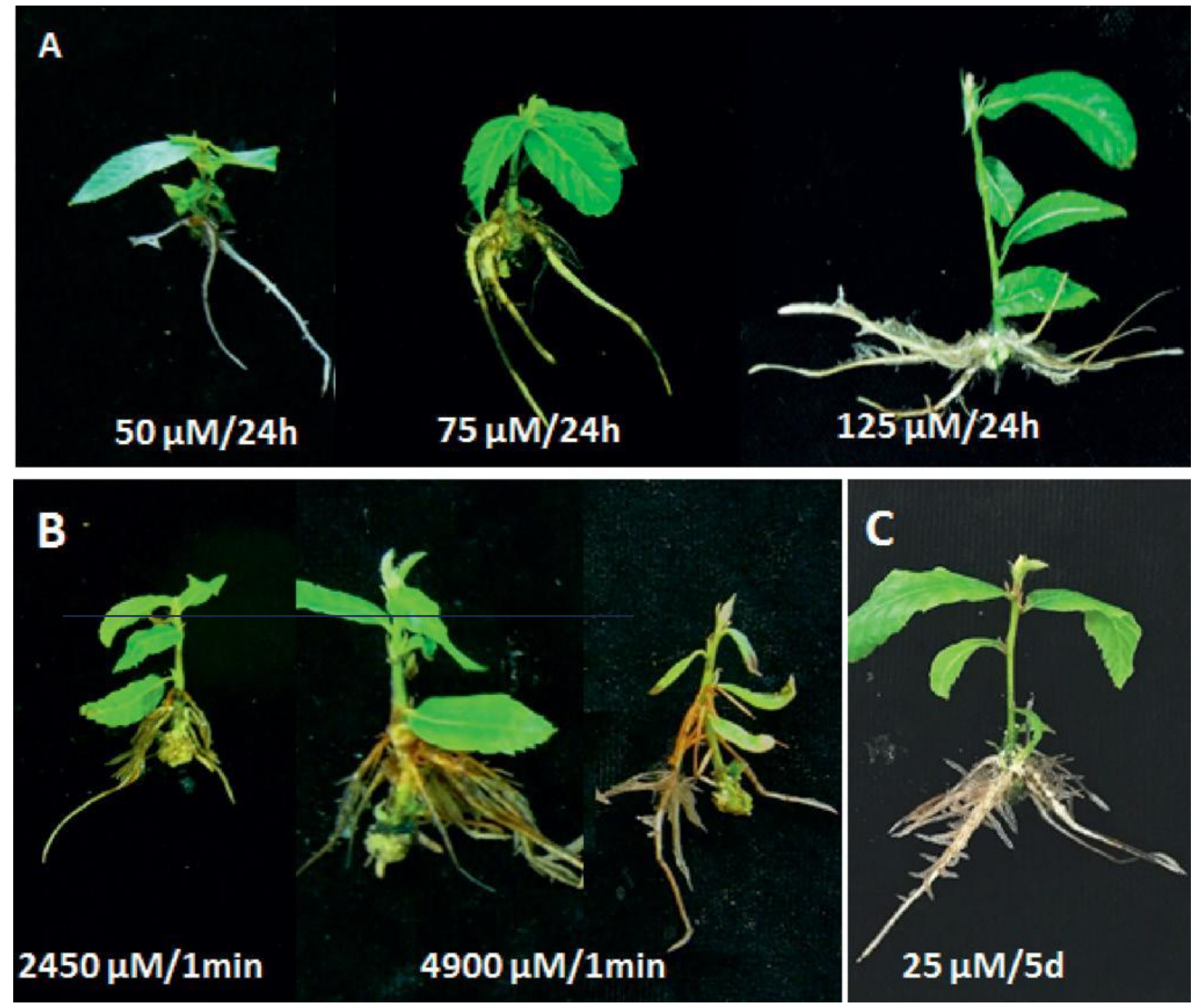

Figure 1. Root system of chestnut shoots subjected to different IBA treatments. (A) P1 shoots treated with 50, 75 and $125 \mu \mathrm{M}$ IBA for $24 \mathrm{~h}$; (B) P2 shoots treated with 2450 or $4900 \mu \mathrm{M}$ IBA for $1 \mathrm{~min}$; (C) P2 shoots treated with $25 \mu \mathrm{M}$ IBA for 5 days. Shoots were transferred to basal rooting medium after the auxin induction treatment for (A and B) 1 month or (C) 25 days. 

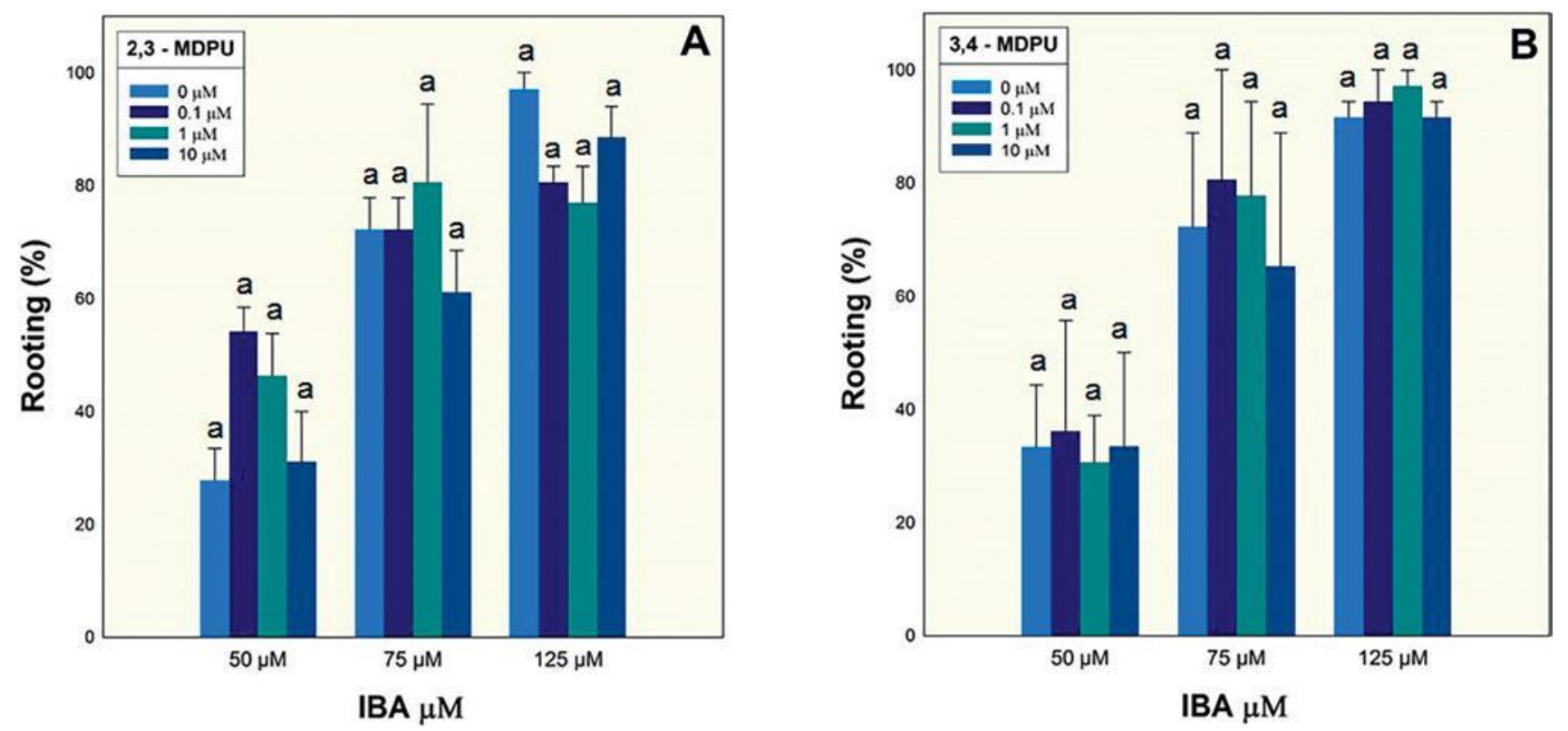

Figure 2. Effect of the presence of MDPU on the rooting percentage of P1 chestnut shoots. Shoots were treated with 50,75 and $125 \mu \mathrm{M}$ IBA in the presence of $0,0.1,1$ and $10 \mu \mathrm{M}$ of either (A) 2,3-MDPU or (B) 3,4-MDPU for $24 \mathrm{~h}$, and subsequently transferred to basal rooting medium for 1 month. For each auxin treatment, different letters indicate significant differences (Kruskal Wallis test).
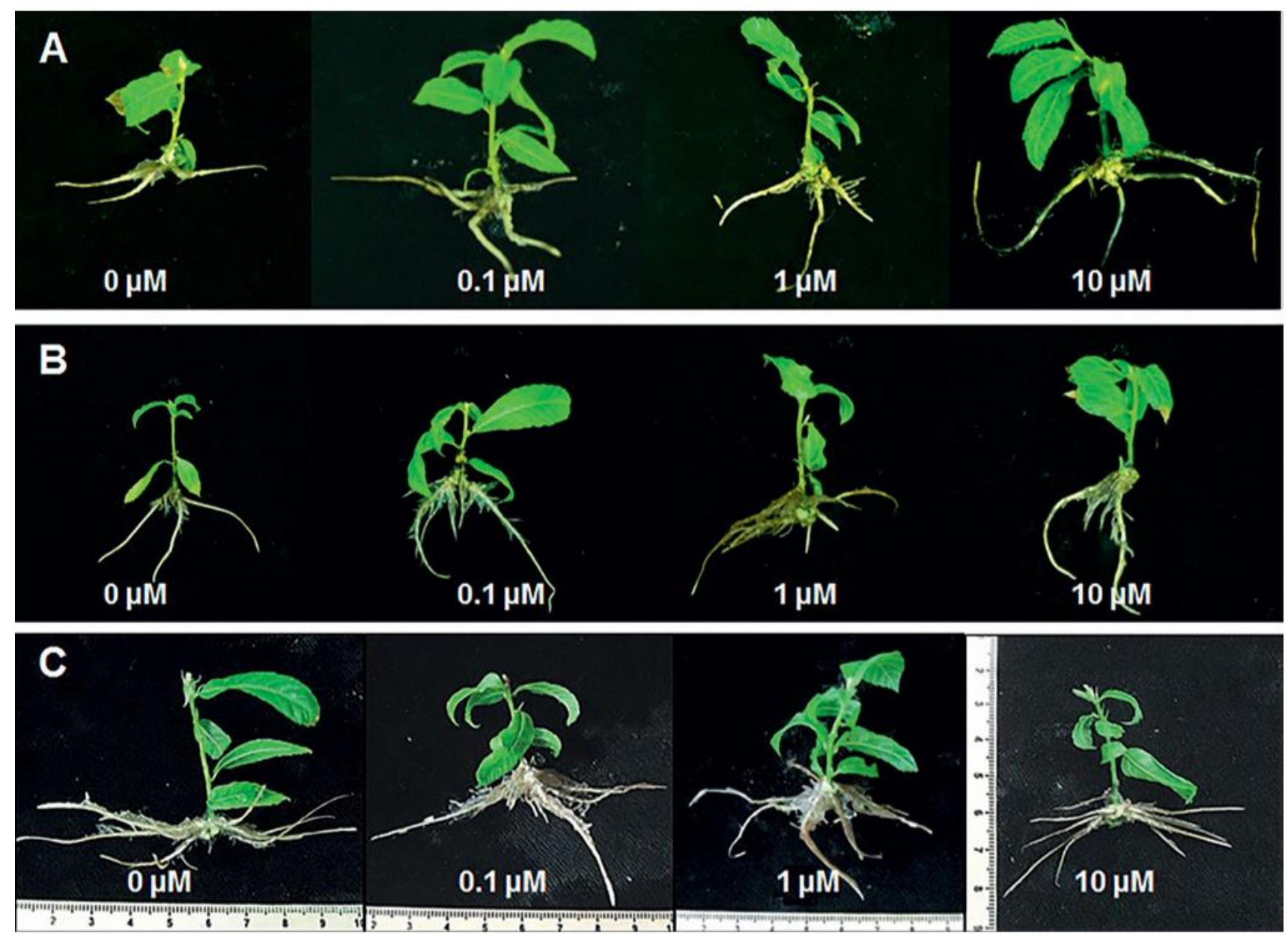

Figure 3. Shoots of P1 chestnut treated with IBA at (A) $50 \mu \mathrm{M}$ (B) $75 \mu \mathrm{M}$ or (C) $125 \mu \mathrm{M}$ for $24 \mathrm{~h}$ in the presence of $0,0.1,1$ or $10 \mu \mathrm{M}$ of 2,3-MDPU. After treatment, shoots were transferred to basal rooting medium for 1 month. 

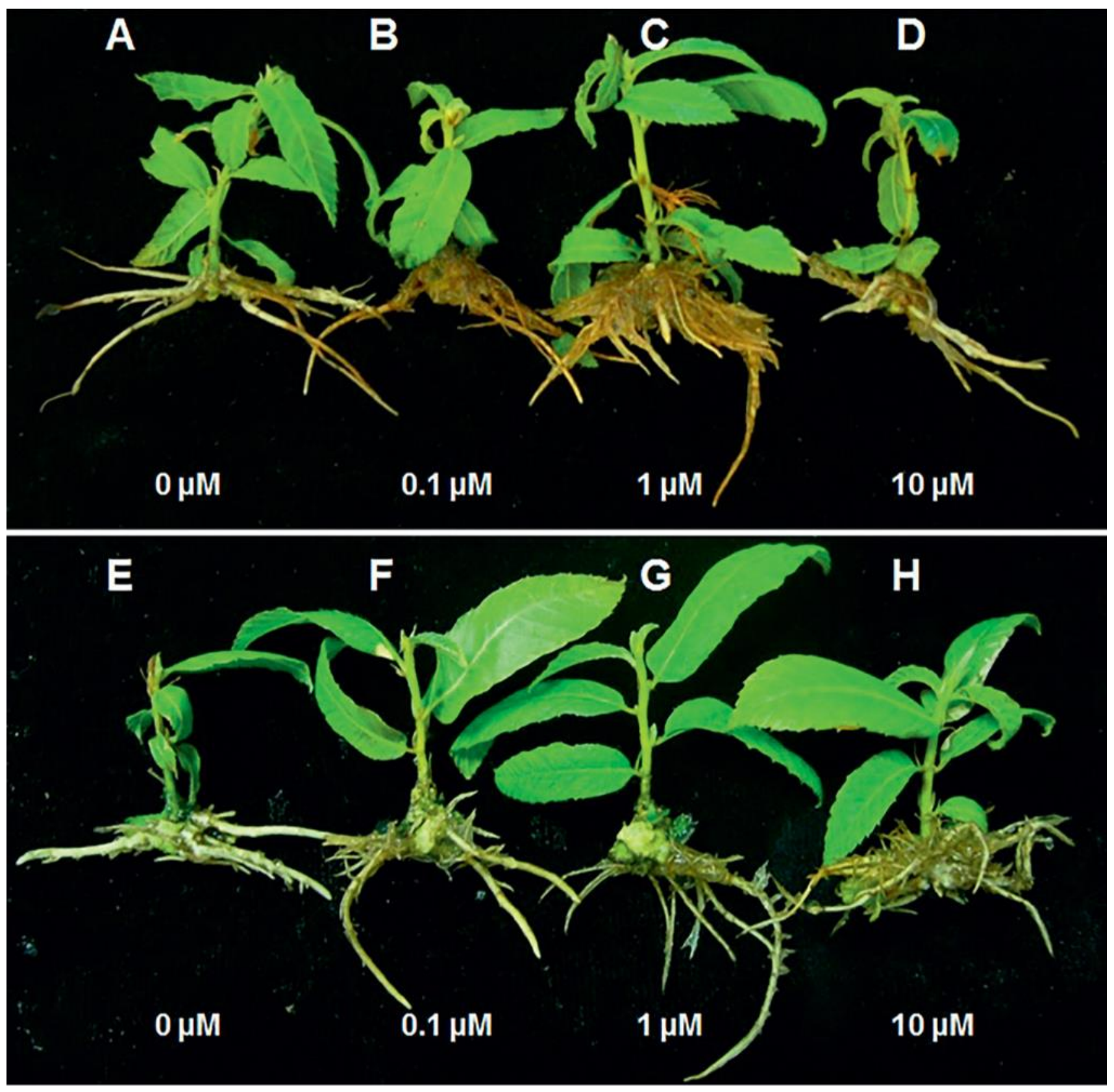

Figure 4. Shoots of (A-D) clone $\mathrm{P} 1$ and (E-H) clone $\mathrm{P} 2$ treated with $75 \mu \mathrm{M}$ IBA for $24 \mathrm{~h}$ in the presence of $0,0.1,1$ or $10 \mu \mathrm{M}$ of 3,4-MDPU. After treatment, shoots were transferred to basal rooting medium for 1 month. 

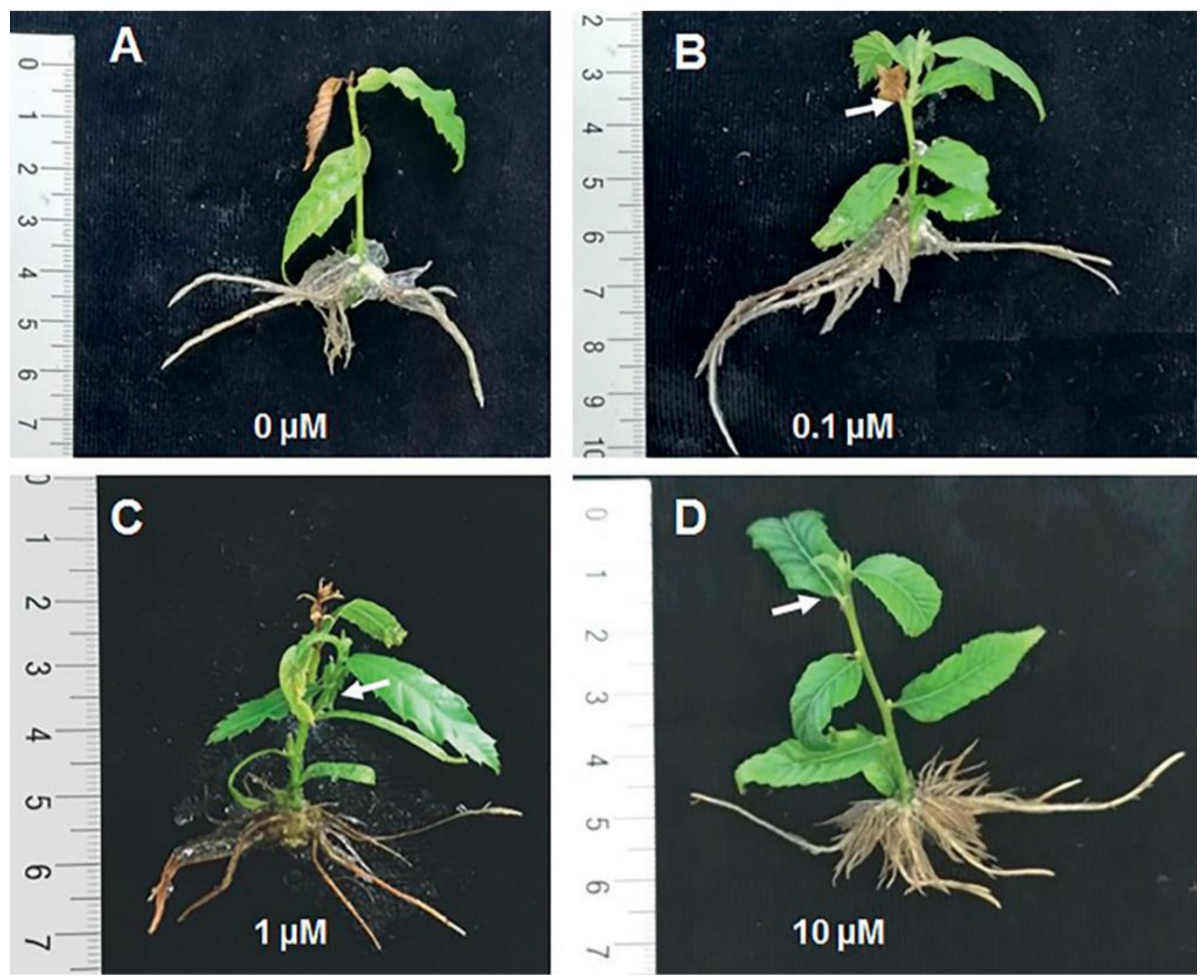

Figure 5. Root development of $\mathrm{P} 2$ shoots treated with $25 \mu \mathrm{M}$ IBA in the presence of (A) $0 \mu \mathrm{M}$, (B) $0.1 \mu \mathrm{M}$, (C) $1 \mu \mathrm{M}$ and (D) $10 \mu \mathrm{M}$ 3,4-MDPU for 5 days. Shoots were then transferred to basal rooting medium for 25 days. The white arrows indicate the new growth. 

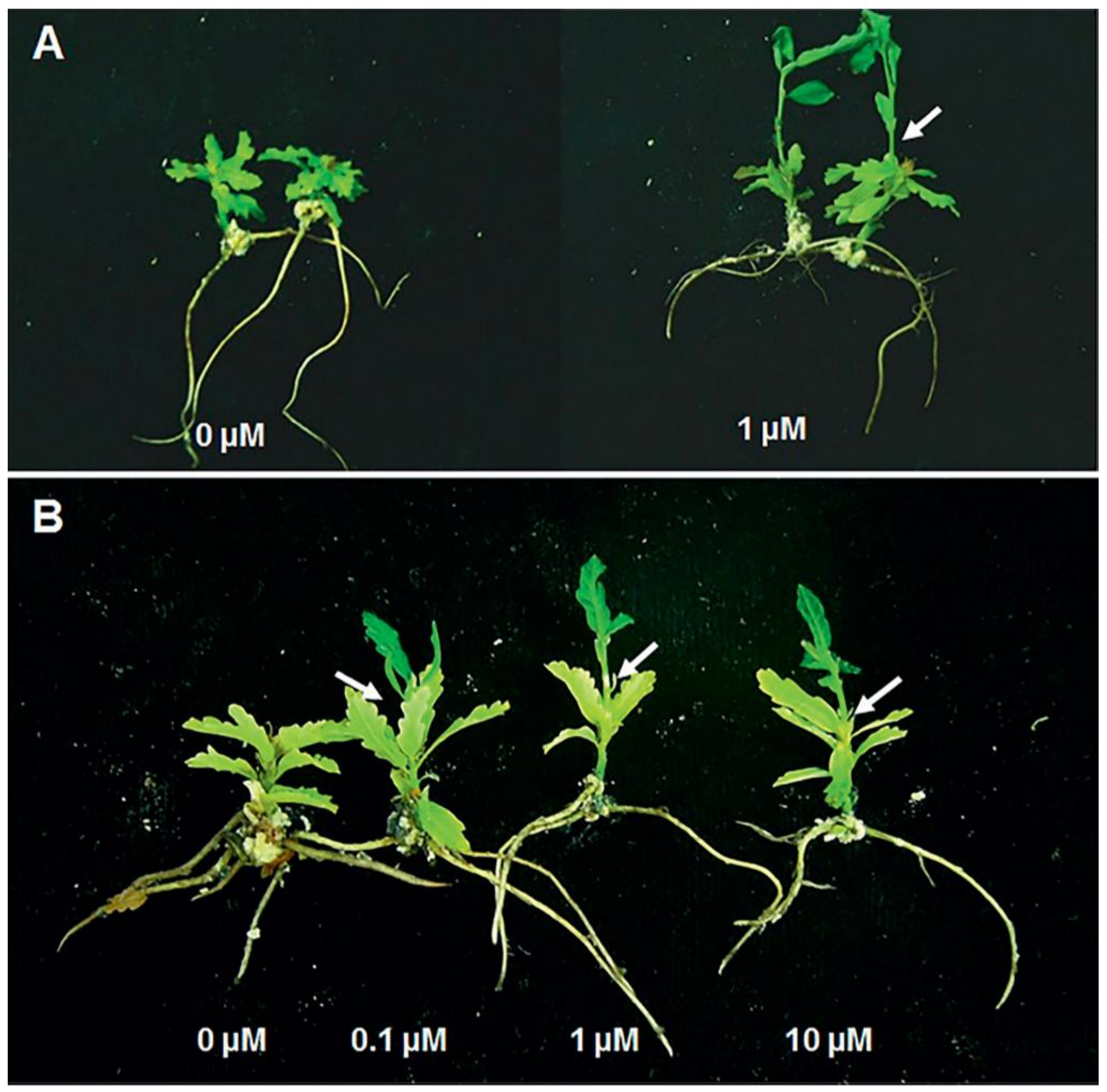

Figure 6. Shoots of oak treated with $75 \mu \mathrm{M}$ IBA for $24 \mathrm{~h}$ in the presence of the indicated concentrations of (A) 2,3MDPU or (B) 3,4-MDPU. Shoots were then transferred to basal rooting medium for one month. The white arrows indicate the new growth. 

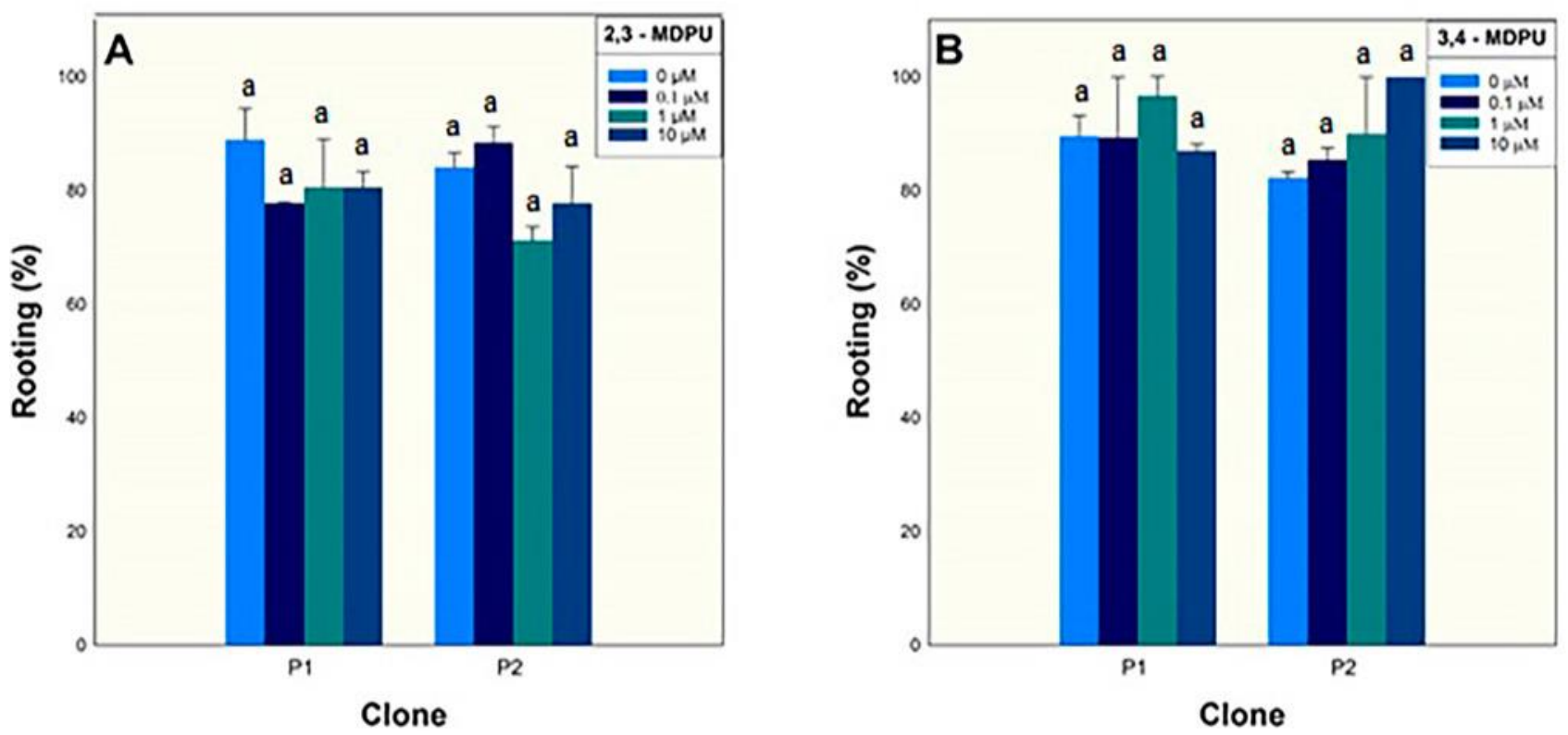

Figure 7. Effect of the presence of MDPU on the rooting percentage in P1 and P2 chestnut shoots dipped in $4900 \mu \mathrm{M}$ IBA for $1 \mathrm{~min}$ and then placed in basal rooting medium containing (A) 2,3-MDPU or (B) 3,4-MDPU for 1 month. For each clone, different letters indicate significant differences (Kruskal Wallis test).
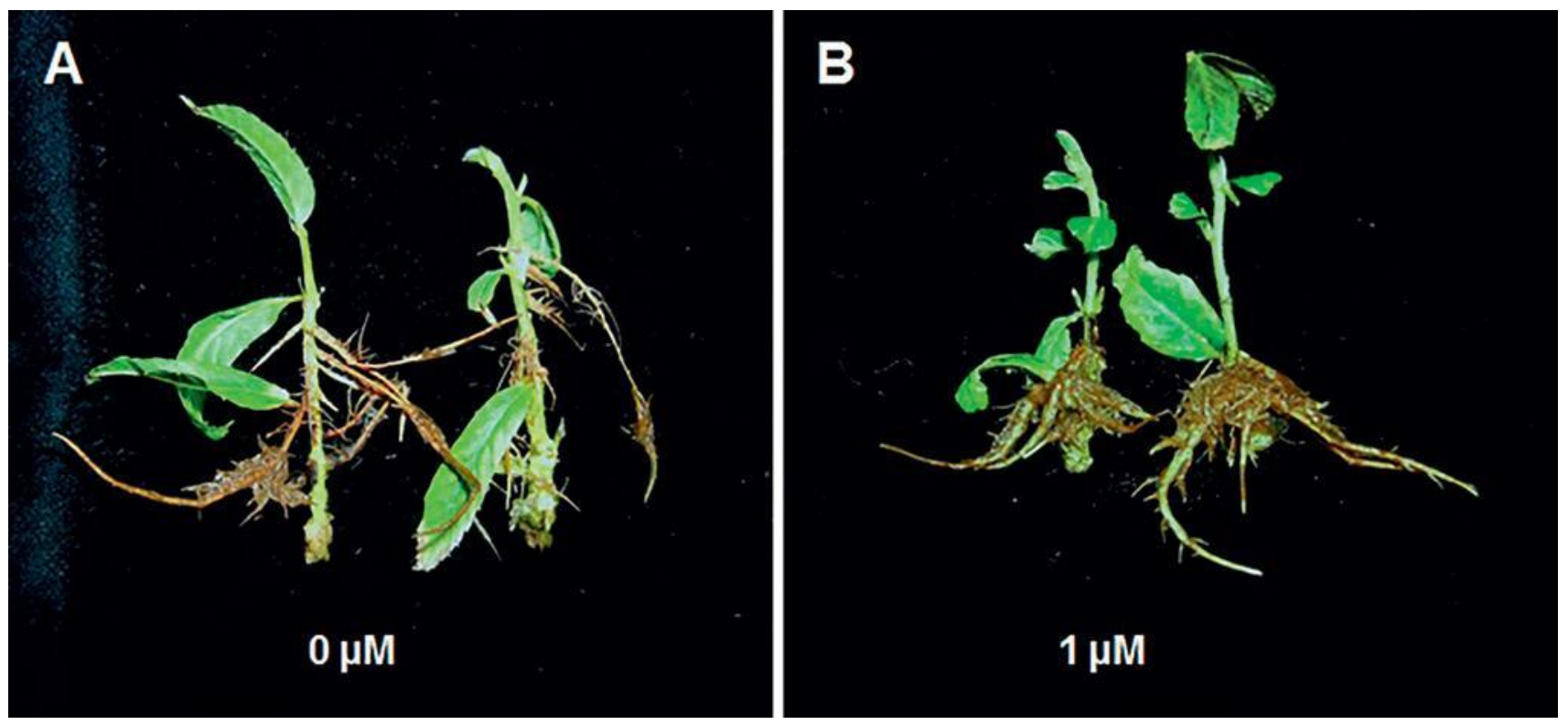

Figure 8. Effect of the continuous presence of 2,3-MDPU in the rooting medium on the root system architecture of chestnut shoots. Microshoots were treated with $4900 \mu \mathrm{M}$ IBA for 1 min and then placed in basal rooting medium supplemented with (A) $0 \mu \mathrm{M}$ or (B) $1 \mu \mathrm{M}$ of MDPU for 1 month. 

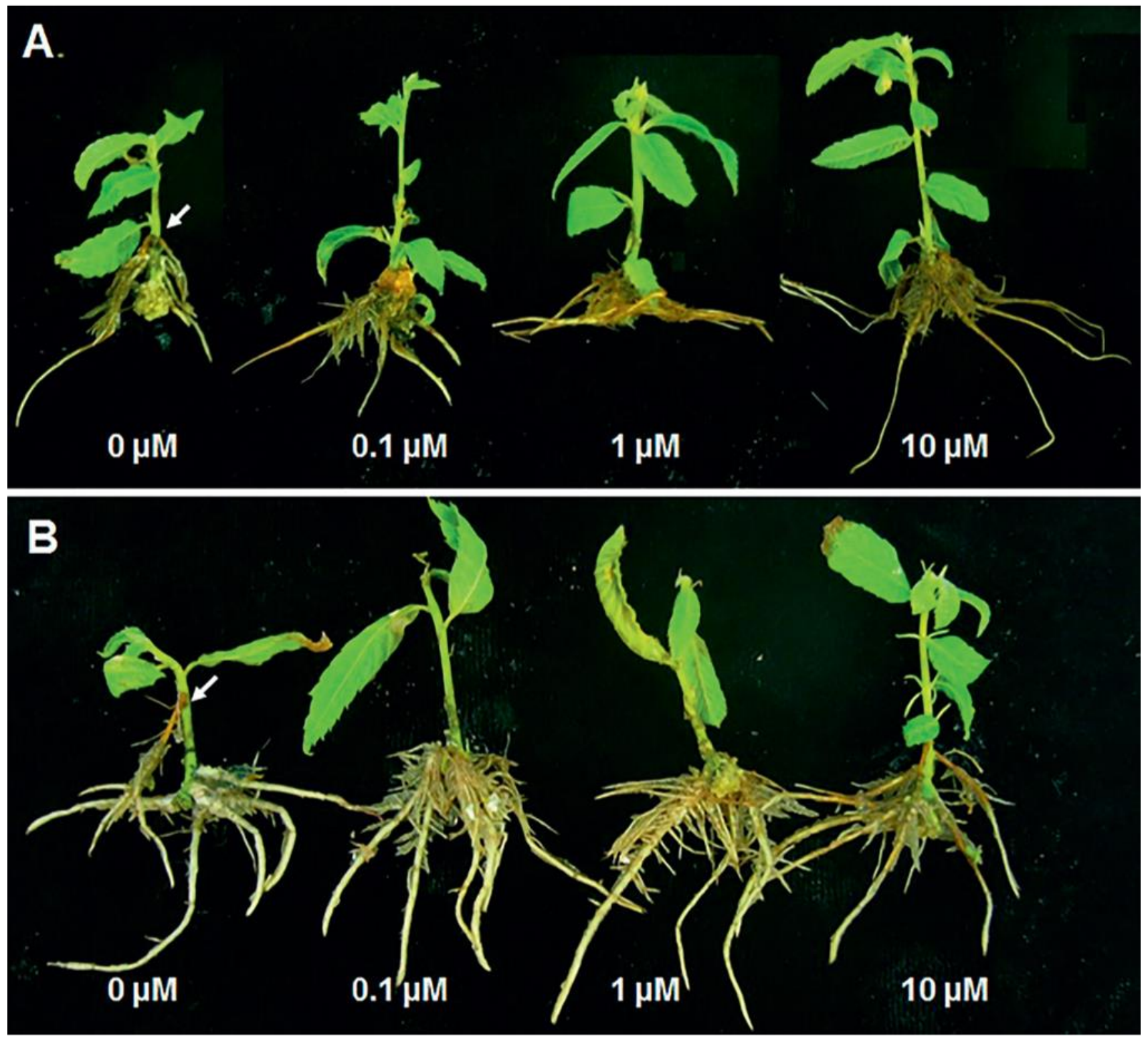

Figure 9. Root development in chestnut shoots treated with (A) $2450 \mu \mathrm{M}$ or (B) $4900 \mu \mathrm{M}$ IBA and placed in rooting medium supplemented with the indicated concentrations of 3,4-MDPU for $24 \mathrm{~h}$. Shoots were then transferred to basal rooting medium for 1 month. The white arrows indicate adventitious roots that developed along the stem. 


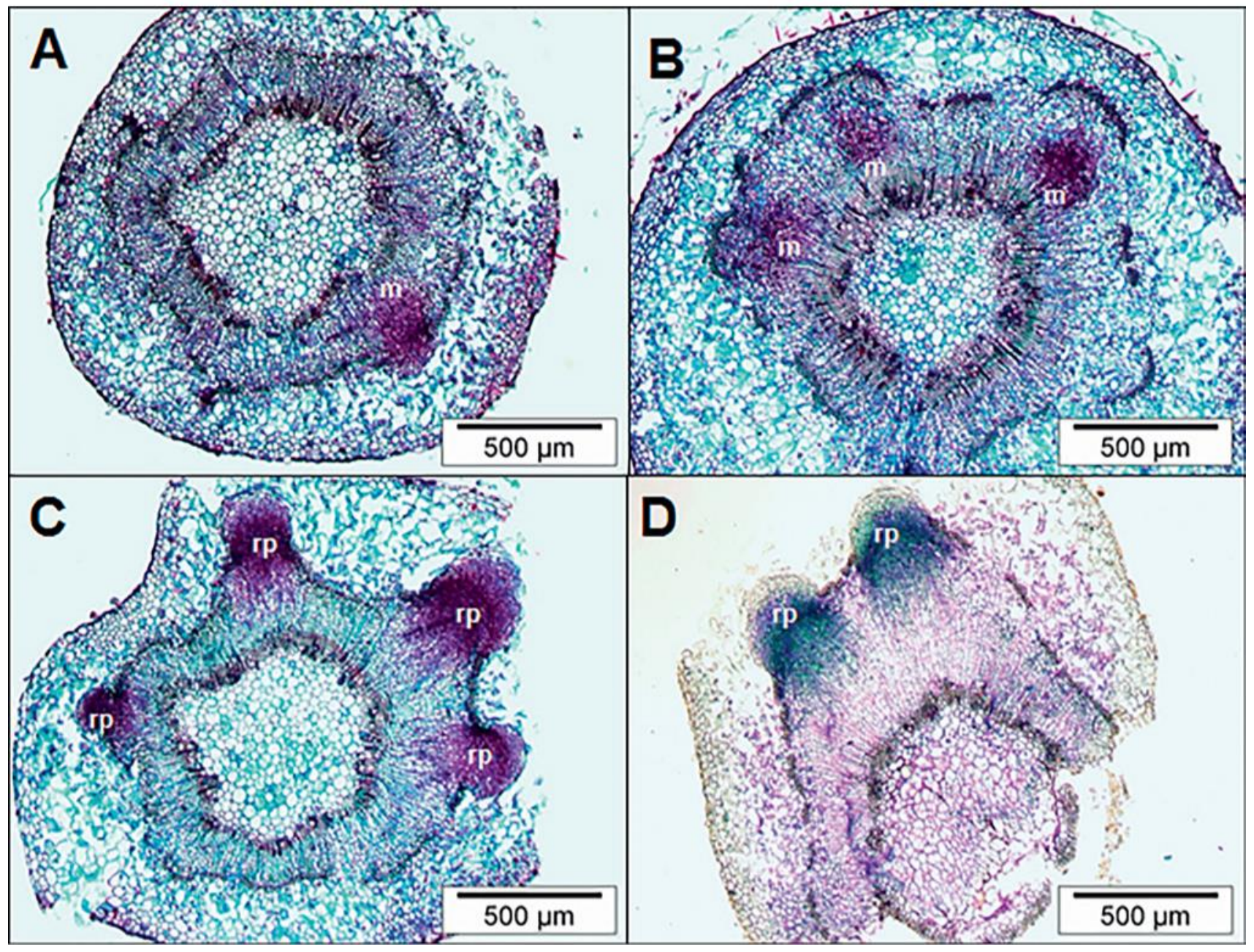

Figure 10. Root meristem development in chestnut microshoots treated with $4900 \mu \mathrm{M}$ IBA for 1 min and subsequently transferred to basal rooting medium with (A) $0 \mu \mathrm{M}$, (B) $1 \mu \mathrm{M}$ or (C, D) $10 \mu \mathrm{M}$ 3,4-MDPU. Transverse sections were obtained on day 5 after root inductive treatment and (A, B, C) 1000-1200 $\mu \mathrm{m}$ further away from the basal end of the shoot or (D) at the basal end of the shoots. m, meristemoid; rp, root primordium. 


\begin{tabular}{|c|c|c|c|c|c|c|c|c|}
\hline \multirow{2}{*}{$\begin{array}{l}\text { Species / Clone } \\
\mathrm{A}\end{array}$} & \multirow{2}{*}{$\frac{\mu \mathrm{M}}{50}$} & \multirow{2}{*}{$\frac{\text { Time }}{24 \mathrm{~h}}$} & \multicolumn{2}{|c|}{ Rooting (\%) } & \multicolumn{2}{|c|}{$\begin{array}{l}\text { Number of } \\
\text { Roots }\end{array}$} & \multicolumn{2}{|c|}{$\begin{array}{l}\text { Longest Root } \\
\text { Length ( } \mathrm{mm} \text { ) }\end{array}$} \\
\hline & & & 30.5 & $\pm 5.3^{c}$ & 2.2 & $\pm 0.4^{\mathrm{c}}$ & 29.0 & $\pm 3.1^{\mathrm{b}}$ \\
\hline & 75 & $24 \mathrm{~h}$ & 72.3 & $\pm 7.2^{\mathrm{b}}$ & 3.5 & $0.6^{\mathrm{bc}}$ & 34.9 & $\pm 2.1^{\mathrm{ab}}$ \\
\hline & 125 & $24 \mathrm{~h}$ & 94.4 & $\pm 2.3^{\mathrm{a}}$ & 5.4 & $\pm 0.6^{\mathrm{ab}}$ & 39.8 & $\pm 1.6^{\mathrm{a}}$ \\
\hline Chestnut / P1 & 4900 & $60 \mathrm{~s}$ & 89.2 & $\pm 2,3^{\mathrm{ab}}$ & 6.6 & $\pm 0.7^{a}$ & 26.2 & $\pm 2.0^{\mathrm{b}}$ \\
\hline B & 25 & $120 \mathrm{~h}$ & 94.4 & $\pm 5.6^{\mathrm{a}}$ & 5.4 & $\pm 0.2^{b}$ & 41.2 & $\pm 0.4^{\mathrm{a}}$ \\
\hline & 75 & $24 \mathrm{~h}$ & 69.5 & $\pm 2.8^{\mathrm{b}}$ & 3.0 & $\pm 0.6^{c}$ & 26.0 & $\pm 4.0^{\mathrm{b}}$ \\
\hline & 2450 & $60 \mathrm{~s}$ & 81.4 & $\pm 1.9^{\mathrm{ab}}$ & 3.9 & $\pm 0.6^{b c}$ & 34.5 & $\pm 2.4^{\mathrm{ab}}$ \\
\hline Chestnut / P2 & 4900 & $60 \mathrm{~s}$ & 89.9 & $\pm 1.7^{\mathrm{ab}}$ & 7.9 & $\pm 0.6^{a}$ & 29.5 & $\pm 0.6^{\mathrm{b}}$ \\
\hline C & 50 & $24 \mathrm{~h}$ & 64.8 & $\pm 13.4^{\mathrm{a}}$ & 2.5 & $\pm 0.3^{\mathrm{a}}$ & 48.2 & $\pm 3.3^{a}$ \\
\hline & 75 & $24 \mathrm{~h}$ & 68.1 & $\pm 7.6^{\mathrm{a}}$ & 2.6 & $\pm 0.1^{\mathrm{a}}$ & 39.5 & $\pm 6.6^{\mathrm{a}}$ \\
\hline Oak / Saínza & 125 & $24 \mathrm{~h}$ & 80.5 & $\pm 2.8^{\mathrm{a}}$ & 3.0 & $\pm 0.2^{\mathrm{a}}$ & 38.7 & $\pm 4.1^{\mathrm{a}}$ \\
\hline
\end{tabular}

Table 1. Effect of the IBA concentration and application period on the rooting parameters of shoot cultures derived from three mature trees. Values are means \pm standard error from at least three replicates. For each variable and clone, the values indicated by the same letter are not significantly different (Tukey-b test).

\begin{tabular}{|c|c|c|c|c|}
\hline 3,4-MDPU $(\mu \mathrm{M})$ & \multicolumn{2}{|c|}{ Shoot Tip Necrosis (\%) } & \multicolumn{2}{|c|}{ Shoot Growth Resumption (\%) } \\
\hline $0 \mu \mathrm{M}$ & 88.9 & $\pm 11.1^{\mathrm{a}}$ & 4.2 & $=4.2^{\mathrm{c}}$ \\
\hline $0.1 \mu \mathrm{M}$ & 63.9 & $\pm 5.6^{\mathrm{a}}$ & 56.6 & $\pm 0.5^{b}$ \\
\hline $1 \mu \mathrm{M}$ & 72.2 & $\pm 7.4^{\mathrm{a}}$ & 53.5 & $\pm 10.8^{b}$ \\
\hline $10 \mu \mathrm{M}$ & 55.6 & $\pm 20.0^{\mathrm{a}}$ & 85.8 & $\pm 8.7^{\mathrm{a}}$ \\
\hline
\end{tabular}

Table 2. Effect of the presence of 3,4-MDPU during the auxin induction period on the quality of rooted shoots. Shoots of clone P2 were treated with $25 \mu \mathrm{M}$ IBA plus 3,4-MDPU for 5 days in darkness and then transferred to basal rooting medium under light conditions. Values are means \pm standard error. For each variable, the values indicated by the same letter are not significantly different (Tukey-b test).

\begin{tabular}{|c|c|c|}
\hline 3,4-MDPU $(\mu \mathrm{M})$ & Shoot Tip Necrosis (\%) & Shoot Growth Resumption (\%) \\
\hline $0 \mu \mathrm{M}$ & $46.8 \pm 1.9^{a}$ & $10.0 \pm 1.1^{\mathrm{c}}$ \\
\hline $0.1 \mu \mathrm{M}$ & $30.7 \pm 2.1^{\mathrm{b}}$ & $30.7 \pm 2.6^{b}$ \\
\hline $1 \mu \mathrm{M}$ & $15.5 \pm 3.8^{\mathrm{c}}$ & $51.7 \pm 4.4^{\mathrm{a}}$ \\
\hline $10 \mu \mathrm{M}$ & $8.3 \pm 3.8^{c}$ & $67.2 \pm 5.1^{\mathrm{a}}$ \\
\hline
\end{tabular}

Table 3. Effect of the presence of 3,4-MDPU during the auxin induction period on the quality of rooted shoots. Shoots of oak were treated with $75 \mu \mathrm{M}$ IBA plus 3,4-MDPU for $24 \mathrm{~h}$ and then transferred to basal rooting medium. Values are means \pm -standard error. For each variable, the values indicated by the same letter are not significantly different (Tukey-b test). 